\title{
Can I jump puddles alone?
}

$\mathrm{T}$ he young man was determined to walk at his graduation ceremony. The background to the television news report was that the young man had been severely disabled. The word paraplegic was not mentioned - only his determination to walk and, almost incidentally mentioned in the report, that he had a wife. When the picture came on the screen, he rose out of his wheelchair and, with his wife supporting him from in front as though he were a statue, he tottered a few steps across the stage. No, he had not walked - his carer had borne his weight and, even though she was half his size, she had held onto him while he made the small distance across the stage. Then the news item was over: no attention to the wife's efforts, and no watching him struggle back to the wheelchair (the wheelchair had probably been moved into a position to avoid the need). He had said that he would walk to obtain his graduation certificate. It was the gritty devotion of his wife - his carer - that enabled him to do it. Good luck — hopefully he will improve; but what struck me was the essential importance of the carer and how little reference was made to her in the news item.

Likewise, had I not had my wife and others to care for me, I would not have been able to work full-time.

I hate being in a wheelchair. Not that I am in a wheelchair that much, but when I have to move more than 100 metres it becomes very difficult without one. What is wrong with the wheelchair? Nothing. I have been surprised by the comfort that a modern wheelchair affords. However, you become a different human being in a wheelchair. Until you make it clear that being in a wheelchair does not mean that your IQ is automatically halved, you tend to be ignored or treated as a child. I remember sitting in my wheelchair and being confronted by a small boy in a stroller. We were at a similar eye level and he, with the ingenuousness of a child, stared at me. To this I responded, "Son, see what awaits you." His parents laughed, but I wondered whether they continue to deny the 5-year-old the use of his legs.

The other option is that you exist in a forest of legs belonging to the able-bodied. You become acutely aware of that facility to walk, which you considered to be an automatic right of homo sapiens. It is compelling to watch the easy facility of movement that you have lost. Watching the striding young man or woman clasping the iPhone to the ear brings home the sheer complexity of the evolutionary trail. There is plenty of time to observe when you are waiting in a wheelchair.

This waiting time is emphasised if you happen to be one of those people who has been both impatient and fidgety. In a wheelchair, impatience is not a wise strategy. Gesturing irritably — especially with a walking stick — is counterproductive!

Likewise, you cannot act on impulse - jump up and do something. Getting to your feet is a considered exercise.

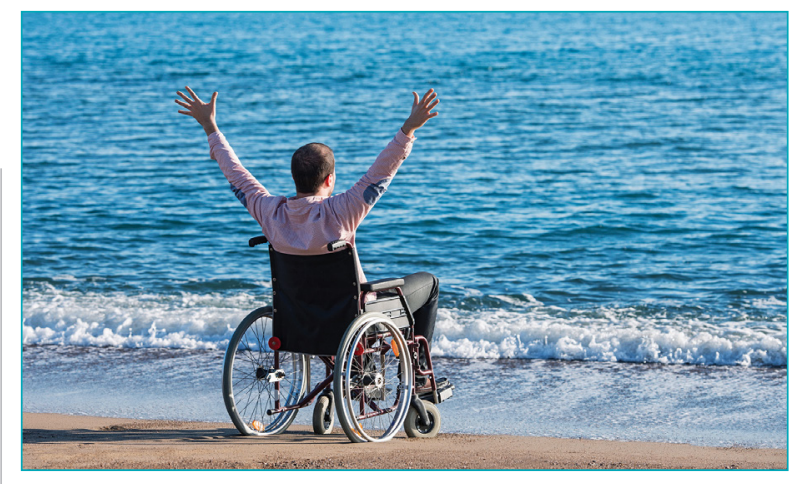

In other words, it is the carers who count in such an environment. Their understanding of the required level of background support is crucial.

This was brought home recently when I decided to walk along the Seattle waterfront from the ferry terminal to the hotel. The Seattle waterfront is undergoing massive reconstruction and therefore hailing a cab is difficult and, in any event, I misjudged both the distance and my capacity. The small boy had decided to get out of his stroller. For about 50 metres with two sticks, it was bearable. However, as I moved forward, the uneven asphalt became jolting potholes; improvised inclines, minor to the able-bodied, are challenging ski runs. I struggled, and my carer kept watch for an hour, hovering and supporting, without saying how stupid I was.

"the uneven asphalt

became jolting potholes"

\section{John B Best
AO, MD BS, PhD, DSC(Hon) \\ University of Melbourne, Melbourne, VIC}

\section{jbbest@iimetro.com.au}

doi: 10.5694/mja15.00667
The occasional person, invariably a young woman, stopped to ask whether I needed help. For an hour, I moved along, away from the dusty, sulfurous fumes and clanging steel of the waterfront, onto quiet civilised pavement. The hotel was in sight and, as usual when walking with sticks, my eyes were mostly directed towards the terrain. What made this segment better was the line of copper beeches; I could count them as I passed each one. I remember when I ran those inaptly named "fun runs" and was getting tired, it was the next telegraph pole in the street or on the highway that was the marker of achievement.

My carer, who had been ever present, suddenly asked whether she could go and get the wheelchair from the hotel since the footpath was paved and the hotel was not more than 200 metres away. She had picked the right moment. I agreed and she disappeared as I slogged on with the vain hope that I would get there before she could bring back the wheelchair. The definition of bliss is being propelled in a wheelchair up to and through the hotel foyer and to the bar for a cold ale.

Caring, as I have found out, and the interaction with the person in care are things that you see; but, unless you are in the situation, you may not feel the importance of that interaction.

However, caring is not the exclusive preserve of some professional group or a financial benefit enshrouded in impenetrable regulation. It is a basic tenet of our society.

It is up to those who are disabled but articulate to advocate for a better deal, not only for the disabled, 
but also for the carers. Neither the carer nor the person being cared for live in parallel. However, a challenge remains: how best to translate that interaction between those who have the interpersonal skills intuitively and those who need to learn the skills to improve the interaction. The internet seems to be full of exhortation as to what is best for the disabled, but there does not seem to be much room for interactive comment.

Yet 300000 carers are younger than 24 years. ${ }^{2}$ I have a 14-year-old grandson who, without prompting, brought me a chair when I needed to sit down. He knew without any words being exchanged what was wanted, because he was paying attention to his environment rather than a piece of technology. As against this was a young girl of similar age, head down and concentrating on her texting, who pushed past me into the lift. Suddenly there was a scream of anguish as the door closed on her. It was fortunate that it was not a railway crossing - or a puddle that turned into a fathom-deep pond.

Competing interests: No relevant disclosures.

Provenance: Commissioned; not externally peer reviewed.

C 2015 AMPCo Pty Ltd. Produced with Elsevier B.V. All rights reserved.

References are available online at www.mja.com.au. 
1 Marshall A. I can jump puddles. Melbourne: Cheshire, 1955.

2 Carers Australia. Statistics. http://www.carersaustralia.com. au/about-carers/statistics (accessed Jun 2015). . 